Original Research Paper

\title{
The Geography of Sex Trafficking and Sexual Exploitation of Children in Minnesota, 2007-2015
}

\author{
Jose Javier Lopez \\ Department of Geography, Minnesota State University-Mankato \\ 206 Morris Hall, Mankato, Minnesota USA, 56001
}

Article history

Received: 21-05-2017

Revised: 08-07-2017

Accepted: 20-07-2017

Email: jose.lopez@mnsu.edu

\begin{abstract}
This article provides a snapshot of the geographic patterns of sex trafficking and sexual exploitation of minors' court cases and the affected communities in the U.S. state of Minnesota. The regional distributions of cases seen in court dealing with solicitation, inducement and promotion of prostitution, solicitation of children to engage in sexual conduct and use of a minor in a sexual performance are compared here. According to the visual examination of the thematic maps and the spatial statistics analyses, the greatest clustering for any of the offenses potentially related to sexual exploitation and trafficking is for cases that involve solicitation, inducement and promotion of prostitution. These clusters are located in Minnesota's major metropolitan areas and transportation hubs. The maps and the spatial statistics dealing with solicitation of a child to engage in sexual conduct and the use of a minor in a sexual performance are less likely to display clusters of cases in metropolitan areas and transportation hubs. In the majority of cases the patterns are random. Based on news reports and the thematic maps' patterns, the Internet has become a centrifugal force that has maintained a considerable number of child solicitation cases happening outside metropolitan areas traditionally linked to other sex crimes such as prostitution.
\end{abstract}

Keywords: Sex Trafficking, Sexual Exploitation, Child Solicitation, Thematic Maps, Spatial Statistics

\section{Introduction}

The solicitation, inducement and promotion of prostitution, sex trafficking and underage sexual exploitation is a problem that has received considerable attention during the past two decades. This problem is to some extent related to the controversial human trafficking global tragedy. Finkelhor (1994, p. 409) notes that until the late $1970 \mathrm{~s}$, the problem of child sexual abuse in North America was "thought to be minor because so few cases were reported." Nevertheless, a growing number of news media and government reports indicate an alarming increase in sexual exploitation cases. According to Hodge (2008), sex trafficking is a major and escalating problem in the larger global community and the United States and it is the largest component of human trafficking. Even though sex trafficking and the sexual exploitation of minors by themselves do not reflect the real extent of human trafficking, the geographic distribution of these crimes can give an idea of which regions have the potential of becoming vulnerable to the presence of facilitators and enablers of this cruel practice. Wilson and O'Brien (2016, p. 39) point out that, "the commercial sex industry as a whole is often implicated as a direct causative factor of human trafficking."

The U.S. is amongst the top ten destinations for human trafficking, "with tens of thousands of people trafficked into the country each year (Hepburn and Simon, 2010, p. 3)." Per U.S. federal laws, human trafficking is "the recruitment, harboring, transportation, provision, or obtaining of a person for labor or commercial sex acts through the use of force, fraud, or coercion (Farrell et al., 2015, p. 316)." Logan et al. (2009) argues that, although human trafficking is receiving increased attention in the U.S., estimates and details about this illegal activity remain elusive. The available estimates of this major social problem's prevalence differ considerably, both by year and by 
source, with tendencies difficult to detect and with tens of thousands of individuals victimized annually but with relatively few incidents reported (Hopper, 2004).

In terms of the trafficking victims' places of origin, the most likely countries are nations plagued by poverty, political instability, large populations of vulnerable women and children and weak institutions where officials can easily be bribed by traffickers (Hodge, 2008). Logan et al. (2009, p. 10) points out that "extreme poverty remains the single most important factor in becoming a target of human trafficking." Nevertheless, Cole and Sprang (2015) observe that in their sex trafficking of minors study in an American state, the most commonly mentioned factors that contributed to victims' vulnerability of being trafficked are compromised parenting and lack of stability in the home. The search for a job, husband, safe haven, or prostitution-related occupations are the pull factors identified by Tyldum and Brunovskis (2005) that motivate the majority of known trafficking victims to travel abroad. According to Hopper (2004, p. 129), the level of vulnerability of the victims increases considerably when they are relocated to lands that are foreign to them, consequently becoming "strangers in a strange land" with no knowledge of the norms and laws of the country where they are experiencing exploitation.

\section{Objective of the Study}

This article provides a snapshot of the geographic distribution of sex trafficking and underage sexual exploitation court cases and affected communities in the U.S. state of Minnesota. To a limited extent, some of these cases have been related to human trafficking. This study has two goals: (1) To shed light on the general characteristics of the regions where the prosecution for these offenses is common; and (2) to examine how similar are the distributions of the three different types of cases dealing with sex trafficking and underage sexual exploitation offenses.

To begin to better understand the problem, a useful first step is to explain Minnesota's statutes associated to cases of sex trafficking and solicitation of children to engage in sexual conduct. Next, I describe the social science literature pertinent to sexual trafficking, including regional dimensions. A literature review of U.S. sex trafficking is presented, with an explanation of how these activities differ from other forms of labor exploitation. Thematic maps show the geographic distribution of counties and communities affected by sex trafficking and child sexual abuse offenses. By focusing on the location of court cases dealing with these offenses, it is possible to determine the regional distribution and geographic extent of offenses connected to the potential for trafficking and exploitation of vulnerable individuals in Minnesota. Based on the concept of the average distance between each case and its nearest neighboring case, I evaluate the degree of clustering of the cases. In addition, I describe the spatial patterns of court cases of sex trafficking and exploitation-related offenses within the state of Minnesota for the periods 2007-2009, 2010-2012 and 2013-2015 using proportional circle maps, dot maps and spatial statistics. The information pertinent to events extracted from these nine years of data is provided by Minnesota's judicial branch.

The data observes where (county) and when (year) a decision was made about sex trafficking and child sexual exploitation charges and in which community the offense occurred. The judicial branch does not provide the specific date the offense occurred, but provide the name of the community where these incidents happened. In addition, this government branch gives the name of the county where a court produced the decision. Based on newspaper articles of the data set's cases, I notice that in most instances the court trials take place between one to two years after the crime was committed. For this reason, I need to emphasize that the dot maps simply show the communities affected by these crimes mentioned in the court cases' records and the time periods in these cartographic products are related to decisions made by the courts and not the year when offenses took place. Consequently, the crime have happened before the time period assigned to the community identified on a particular dot map. I conclude the examination of maps and spatial statistics with a discussion of the regional patterns' differences between the three court cases' time periods.

When it comes to data compiled by law enforcement agencies in Minnesota, there is not one arresting charge that captures all human trafficking-related offenses (MOJP, 2014). Hopper (2004) has noted that many trafficking crimes continue to be prosecuted under statutes not directly related to trafficking. For this reason, I rely on data about court cases dealing with three statutes that involve offenses associated with human trafficking and sex trafficking of minors. The specific statutes selected to examine the geographic distribution of cases seen in Minnesota's courts that have been related to sex trafficking and child sexual exploitation are the following:

- 609.322 Solicitation, Inducement and Promotion of Prostitution; Sex Trafficking

- $\quad 609.352$ Solicitation of a Child

- 617.246 Use of a Minor in a Sexual Performance

The information about charges and convictions pertinent to these statutes is a product of the State Court Administrator's Office. I have divided this data for court cases and convictions from 2007 to 2016 over three periods: 2007-2009, 2010-2012 and 2013-2015. I 
selected these statutes because as Hepburn and Simon (2010, p. 8) note, some victims of human trafficking in the U.S. are trafficked within the country mainly for the purpose of commercial sexual exploitation. Also, government reports tend to produce narratives that "construct victimization as occurring predominantly within the commercial sex industry (Wilson and O'Brien 2016, p. 43).” In numerous occasions, vulnerable women and minors gravitate toward traffickers who use questionable or "false front" employment, modeling offers, or marriage agencies that promise potential victims a better future (Hodge, 2008, p. 145).

One factor that makes the study of sex trafficking more feasible for analysis than other forms of human trafficking and exploitation is the level of visibility of the sex trade. It is easier for police agencies to investigate and charge sex workers because the participants of this form of trafficking usually interact with the public in open spaces, thus making them more visible than people forced to work and live in a closed factory or perform domestic services (Logan et al., 2009). In addition, Hepburn and Simon (2010, p. 21) observe that law enforcement agents are better aware of useful resources when it comes to "identifying human trafficking for the purposes of commercial sexual exploitation as opposed to forced labor." Consequently, there is more data for researchers to study sex traderelated human trafficking than labor exploitation human trafficking. According to Batsyukova (2007), the sex industry is more visible than domestic servitude and organ trafficking. Unlike the invisible nature of involuntary servitude, human trafficking-related prostitution is more observable:

Women operating in known areas for prostitution can relatively easily be observed and counted. Even women in situations of serious exploitation and abuse can never be totally invisible in the prostitution arena, as their organizers need to sell the women to clients. (Tyldum and Brunovskis, 2005, p. 26)

Statutes dealing with crimes in which children are victims tend to produce relatively more reliable data than cases pertinent to other forms of exploitation involving adult victims; this is because district attorneys are usually more aggressive prosecuting those accused of abusing minors. "The commercial sexual exploitation of a minor is generally uncontested as a crime by the public and easier to prosecute in court (Farrell et al., 2015, p. 318)." Finkelhor (1994, p. 413) has noted that in every country where investigators have asked about child sexual abuse, they have found that a significant portion of the adult population, "measurable in simple survey of adults," admit a history of this form of abuse regardless of the levels of publicity about the problem. Children are particularly vulnerable and Ugarte et al. (2004) have noted that whenever minors are illegal immigrants, they are usually at the mercy of labor traffickers who facilitate the children's crossing of the border while luring them with false promises of jobs and deprive them of their freedom by treating them as slaves. According to Logan et al. (2009), numerous trafficked individuals believe they will be hired by legitimate employers who will assign tasks such as waitressing, horticultural work, domestic services, or childcare, but eventually many find out when they arrive they were deceived. Hopper (2004, p. 130) identifies young age as a likely "risk factor that increases vulnerability of being trafficked and decreases the likelihood of reporting the crime." In addition, Ugarte et al. (2004, p. 150) have observed, "children who are unaccompanied migrants or who have run away from abusive homes are at especially high risk for prostitution/trafficking." Tyldum and Brunovskis (2005) have shown that it is necessary to draw a distinction between the stages that a victim of trafficking can occupy in relation to the trafficking process in order to determine the extent of the problem. Their first stage concerns with the type of person at risk of being trafficked, which in a considerable number of cases children are the most likely victims (Tyldum and Brunovskis, 2005, p. 21). In some situations, children run away from their homes due to family violence, sexual assault and physical abuse. Consequently, becoming homeless and prostituting themselves for food, shelter and money they can send to relatives in need (Ugarte et al., 2004; Logan et al., 2009). One tragic reality about the U.S. that makes this country an important destination of trafficked minors is the massive size of its child pornography industry (Hodge, 2008).

\section{Background}

Some social scientists have focused their attention on the question on why criminal organizations have selected sex trafficking and exploitation of minors as their illegal enterprise. According to Hepburn and Simon (2010, p. 21), "from a cost-benefit analysis, trafficking is low risk and has high profit margins." For many traffickers, this activity is more convenient that drug dealing because individuals sold into the sex industry make money for their procurers for a number of years, unlike the profits made from the sale of illegal drugs, which are sold and used once (Hodge, 2008). In addition, victims themselves are expected to pay their abusers for such a traumatic experience:

Trafficking in humans is profitable for several reasons. First, traffickers gain from fees charged to the trafficked victim as well as from the profits from the victims' labor. Traffickers maximize their profits by keeping 
their costs low. Costs are minimized by not paying victims or by paying them very little... In addition, the lack of identification, prosecution and sentencing of perpetrators for trafficking in humans make this kind of crime particularly profitable and low risk for the trafficker. (Logan et al., 2009, pp. 5-6)

The data examined here has limitations and finding statistics about sex trafficking is challenging. According to Tyldum and Brunovskis (2005), reliable and comprehensive data about the victims' identities is rare and its production is resource draining. Hepburn and Simon (2010), for instance, have noticed that a common concern among social service providers is the number of vulnerable immigrants who are found in law enforcement raids, arrested and deported without assessing whether they are in fact trafficking victims. Farrell et al. (2015, p. 317) argue that the prevailing but erroneous notion that human trafficking is not a local issue "allows local law enforcement agents to avoid developing a sophisticated understanding of the elements that distinguish trafficking as a criminal offense." Many police agents believe that the traffickers and those who are trafficked are simply outsiders moving constantly over a vast territory without involving local populations. Logan et al. (2009) point out that one misunderstanding about human trafficking, associated to the term itself, is that victims must be moved over the geographic space in order to meet definitional criteria pertinent to the problem's legal description. In addition, the immigrant status of many of the victims have compelled many experts to acknowledge that:

Smuggling and trafficking, by definition, involve a sense of secrecy due to the fact that individuals are often brought into the country illegally. Traffickers utilize this secrecy to maintain control over their victims. (Hopper, 2004, p. 129)

For this reason, government data misses a significant number of trafficking victims. In essence, when dealing with those involved in human trafficking, researchers have upon them what Tyldum and Brunovskis (2005, p. 18) call "hidden populations." These populations include sex workers, traffickers, victims/survivors and illegal immigrants, "for whom the size and boundaries are unknown and for whom no sampling frame exists (Tyldum and Brunovskis, 2005, p. 18)." According to Hopper (2004, p. 131), "trafficking victims have traditionally been treated as illegal aliens who are subject to deportation." Government reports are likely to underrepresent the true nature of the issue because it is challenging to estimate how many "marginalized" individuals are victims of this trade (Logan et al., 2009, p. 6).

One of the many obstacles limiting public awareness of sex trafficking and sexual exploitation of children is the attitude the general population and law enforcement personnel have toward the problems marginalized populations and immigrants face. Among several factors Hopper (2004, p. 131) identifies as responsible for "underidentification" of human and sex trafficking victims is law enforcement and other related entities' lack of knowledge about these illegal trades. According to Farrell et al. $(2015$, p. 316$)$, the police struggles with the definitional ambiguities of trafficking problems and there is a lack of an "investigative culture" that supports the identification of human exploitation cases. In accordance with Ugarte's et al. (2004, p. 149) research, although trafficking is in fact a human rights violation, victims of trafficking have been prejudicially dismissed as a "problem" of illegal migration. There are numerous reports describing instances where government agencies discover the presence of illegal immigrants, who are victims of human trafficking, but the government's reaction is to deport them, even though they can serve as witnesses in cases against traffickers (Hepburn and Simon, 2010). As a result of this practice, cases against human traffickers can be very weak and convictions are less likely to happen.

There have been instances in which victims of trafficking seek help, only to be treated like criminals by the authorities rather than as victims of sexual exploitation. As a result, these vulnerable individuals end up feeling more "marginalized (Hodge, 2008, p. 148)." Law enforcement's lack of understanding of the human trafficking tragedy also includes the tendency among police agents of labeling victims of trafficking as prostitutes. This tendency derives from the absence of knowledge and training among police agencies and related government agencies on how to distinguish sex trafficking from prostitution (Batsyukova, 2007). According to Logan et al. (2009), police agents oftentimes do not investigate beyond the visible aspects of criminal activity and fail to determine whether human trafficking is part of a largear problem, or a local issue. As a result of this form of investigative neglect, some human trafficking victims are left identified as criminals. Every time police agents label a victim of trafficking and sexual exploitation as a prostitute, a new barrier against the development of reliable data about human trafficking is created because of the victims' unwillingness to cooperate due to stigmatization concerns (Tyldum, 2010). In addition, the complicated nature of the political and legal aspects pertinent to prostitution, labor market protection and immigration laws further complicates the issues (Tyldum and Brunovskis, 2005, p. 18). As 
Logan et al. (2009, p. 4) reports, "there seems to be less governmental and policy concern about human trafficking than there is about international terrorism or the legality of immigration."

In addition, law enforcement and government personnel misconduct have created a climate of mistrust in some communities. In some instances, victims of sex trafficking are unwilling to report exploitation because they fear corrupt police and government employees. Cases of police and state employees involved in misconduct like the selected offenses for this examination of sex trafficking-related crimes are not uncommon in Minnesota. For example, one of the most seriously affected regions by the use of minors in sexual performances is the northeastern part of the state. An incident with the potential of eroding public trust in that part of Minnesota is the case of a former Itasca county sheriff's deputy, who worked as a sex crimes investigator, sentenced in 2010 to 12 years in prison for sexually abusing a teenager over several years (Associated Press, 2010).

Fear of law enforcement institutions is reinforced when victims are treated like lawbreakers or illegal immigrants because of lack of broad police training in recognizing human trafficking victims (Hepburn and Simon, 2010; Hopper, 2004). Female illegal immigrants usually avoid seeking social services for fear of being apprehended and deported by Immigration and Naturalization Services (Ugarte et al., 2004). Other factors that make difficult the process of identifying human trafficking victims are the covert nature of the activity, language and cultural barriers, victims' lack of knowledge about their rights and isolation (Logan et al., 2009, p. 16). Poor English language skills, absence of translators, lack of bicultural/bilingual professionals and nonexistence of reading materials in the native language of sexual exploitation victims limit access to information about rights, services and options for these individuals, therefore increasing a feeling of captivity (Ugarte et al., 2004). Additionally, developmental issues may also affect victims' abilities to collaborate with the investigation and prosecution of trafficking cases (Hopper, 2004).

Hepburn and Simon (2010) notice that in some situations prosecutors feel more inclined to utilize direct charges such as sexual assault, aggravated assault and kidnapping against traffickers since they were more successful in the past convicting these offenders when they used these "tried and true" charges. Prosecutors are more likely to expect harsher sentences for defendants if they avoid recently produced antitrafficking laws that have not been tried successfully in the recent past. Another issue related to the data derived from police and the legal system is the use of biased selection criteria. These subjective selection principles consider victims' willingness to testify, the desire of the authorities from the victims' countries of origin to cooperate during the legal process and the exclusion of cases that are perceived as lacking of strong elements of coercion (Tyldum, 2010, p. 6). Basically, these issues influence which individuals are more likely to be perceived as victims. In addition, anti-trafficking efforts are relatively new and the federal government began aggressive anti-trafficking campaigns recently, in 2005 (Hepburn and Simon, 2010).

Even though the limitations listed above might discourage researchers from investigating prostitution and child solicitation-related human trafficking, the limited information available still can serve as a good start for the process of understanding the geographic dimensions of the problem. The limitations are real but possibilities for analysis are concrete too:

...any data production among victims of
trafficking will be associated with some
kind of bias or limitation. This does not
mean that we should abandon them and the
project of producing data on victims of
trafficking as such. In this article I have
discussed different sources and strategies
for collecting data on human trafficking and
in spite of their limitations, many of them
can give potentially interesting and valuable
data. However, they should not be expected
to be without bias... (Tyldum, 2010, p. 10)

Ugarte et al. (2004, p. 148) identify massage parlors, strip clubs, escort agencies, lap dance clubs, particular streets, vehicles, motels, or tents set up at the edge of farm fields as places where prostitution and trafficking can take place and pimps will move the victims to "wherever there is a demand for prostitution, for example military bases, tourist destinations, conventions or migrant communities."

\section{Research Methods}

This study seeks to resolve questions pertinent to regional patterns of human trafficking-related offenses in Minnesota by examining court records' data sets from this state's judicial branch and providing spatial statistical description of this social problem. I am examining the justice system's regional responses to solicitation, inducement and promotion of prostitution, solicitation of a child to engage in sexual conduct and use of a minor in a sexual performance. Whenever authorities deal with these cases in court, they are dealing with one of the possible government's responses to this problem and my central aim involves the examination of geographic 
and temporal variation in the prosecution of these offenses. My goal is to gain a better notion of which regions of Minnesota are more likely to be affected by these issues.

Two important steps of the geographic representation of the problem involve mapping the data acquired from the judicial branch. First, for the number of cases dealing with the designated statutes per county I use the proportional symbol approach and circles have been selected as the symbol form. Each circle varies its size from county to county, in proportion to the number of court cases. This graphic representation helps us form a mental image of the quantitative distribution of court cases by evaluating the distribution of differently sized circles. Second, dots indicating the absolute location of communities affected by the selected offenses are placed inside each county that houses the prosecuting agency. The dot maps reveal uniquely arranged distributions within the counties. Also, these maps show distributions of cases characterized by sparseness, clustering, or linearity.

In addition, dot maps permit us to conduct a point pattern analysis using the nearest neighbor approach for determining the spatial arrangement of the human trafficking-related cases. Basically, I look at the distance that exists between an affected community and its nearest neighboring affected community; then I repeat this measuring step for the other communities that reported court cases of this nature and these distances to each Nearest Neighbor (NND) are measured from the map. From the set of nearest neighbor distances, the average nearest neighbor distance is determined and I compare this average value for the observed pattern to the expected average produced from a certain distinct point distribution that hypothetically indicates a random spatial pattern, which is the average nearest neighbor distance in a random pattern (McGrew et al., 2014). These average values allow me to calculate the nearest neighbor statistic, denoted as letter $\mathrm{R}$, which is defined as the ratio between the observed and expected average nearest neighbor distances (Rogerson, 2015). The value of $\mathrm{R}$ can vary between 0 and 2.15 , with values close to zero indicating a clustered pattern and values close to 2.15 indicating a dispersed pattern (Burt et al., 2009). With the assistance of this quantitative method I can determine if the case patterns are more clustered than random for any of the three periods examined here.

\section{Resultant Geographic Patterns}

An important component of the present article is the mapping of county level data relevant to the solicitation, inducement and promotion of prostitution, solicitation of children to engage in sexual conduct and use of a minor in a sexual performance. As Tyldum (2010, p. 4) points out, "mapping and monitoring of prostitution arenas (their size and organization) can be crucial in order to understand trafficking for prostitution." Logan et al. (2009, p. 24) argues that research of this nature is "needed to capture the geographic clustering of victims in the United States, to better inform outreach and education strategies." Tyldum (2010, p. 10) emphasizes that knowing research and data that reveal the geographic location of human trafficking affected areas can help us to "target programmes and policies; and monitor how the extent and content of trafficking changes in order to evaluate existing policies."

Minnesota is geographically partitioned into 87 counties (Fig. 1). The proportional circle maps produced with the number of cases seen in court dealing with solicitation, inducement and promotion of prostitution and solicitation of children to engage in sexual conduct are suitable to form a picture of the quantitative distribution of these offenses by observing the patterns of differently sized circles. For the first period, 20072009 map (Fig. 2), which deals with solicitation, inducement and promotion of prostitution, the frequency of counties with a measurable number of court trials is very small. Basically, only three counties in the Minneapolis-St. Paul Twin Cities metropolitan area reported court cases. However, for the second period, 2010-2012 map (Fig. 3), I start to notice that few counties outside the Twin Cities area are reporting cases seen in court dealing with prostitution-related incidents. Two of these counties outside the Twin Cities area, Olmsted and St. Louis, have the third and fourth largest cities respectively in the state of Minnesota.

As Fig. 2 and 3 show, court cases that involved solicitation, inducement and promotion of prostitution have a connection with the urban character of these regions. Cities such as Minneapolis (Hennepin County), St. Paul (Ramsey County), Rochester (Olmsted County) and Duluth (St. Louis County), which are in the counties with the largest circles in Fig. 2 and 3, tend to have a significant transient population, which can contribute to the presence of relatively lenient authorities when it comes to prostitution-related activities (Hubbard and Sanders, 2003). However, the subsequent map reveals a visible spread of cases (Fig. 4). Three counties in west central Minnesota report six court cases involving prostitution related offenses. These counties have a distinction in common: Being at the center of major transportation corridor, following Interstate Highway 94. This road is heavily used as a trucking route and major railroads cross the counties of this region. The association between railroads and prostitution has been identified by McKewon (2003) who found in historic records for Perth, Australia that sex workers operated close to railway lines. 


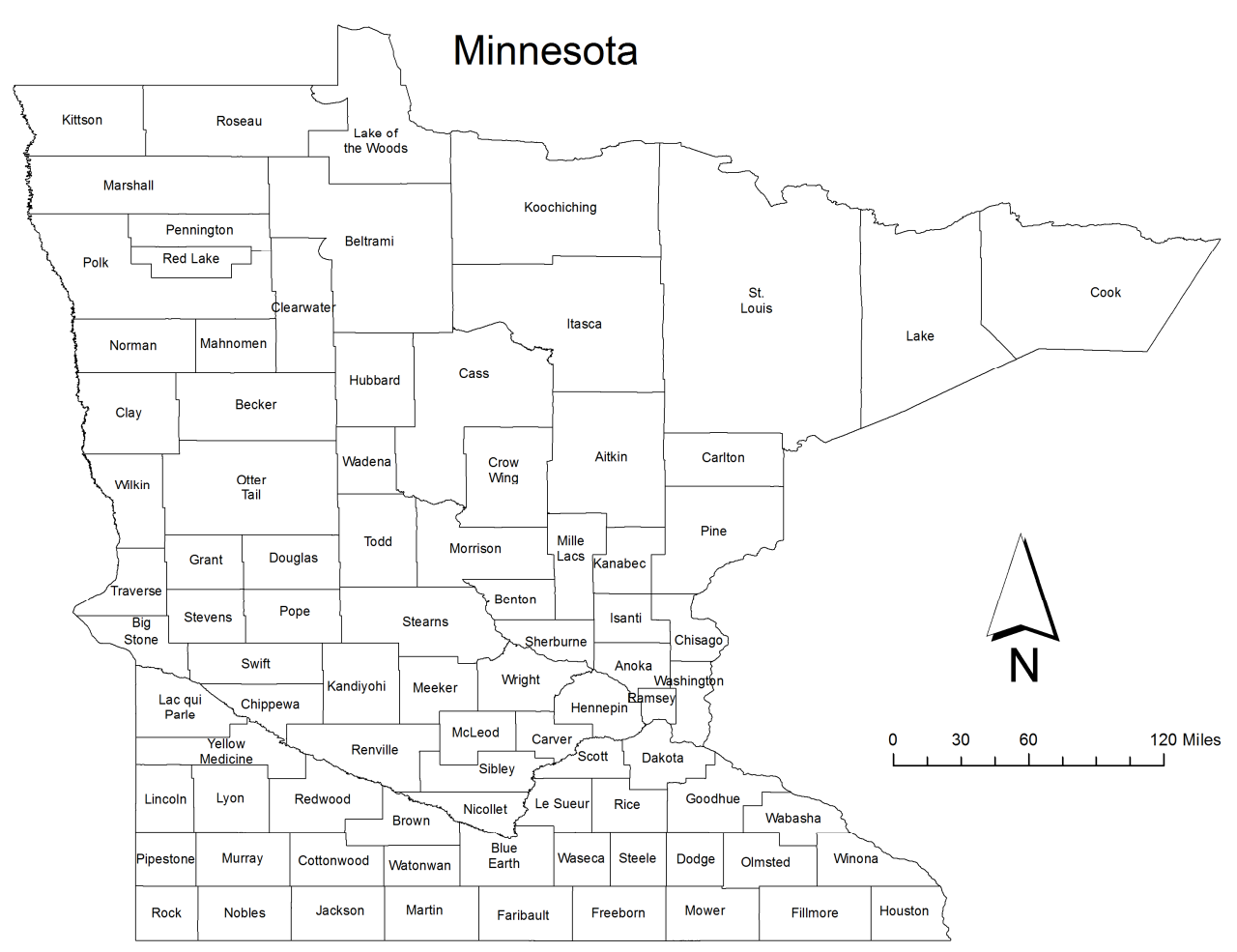

Fig. 1. This state is geographically partitioned into 87 counties

Solicitation, Inducement, and Promotion of Prostitution:

Sex Trafficking

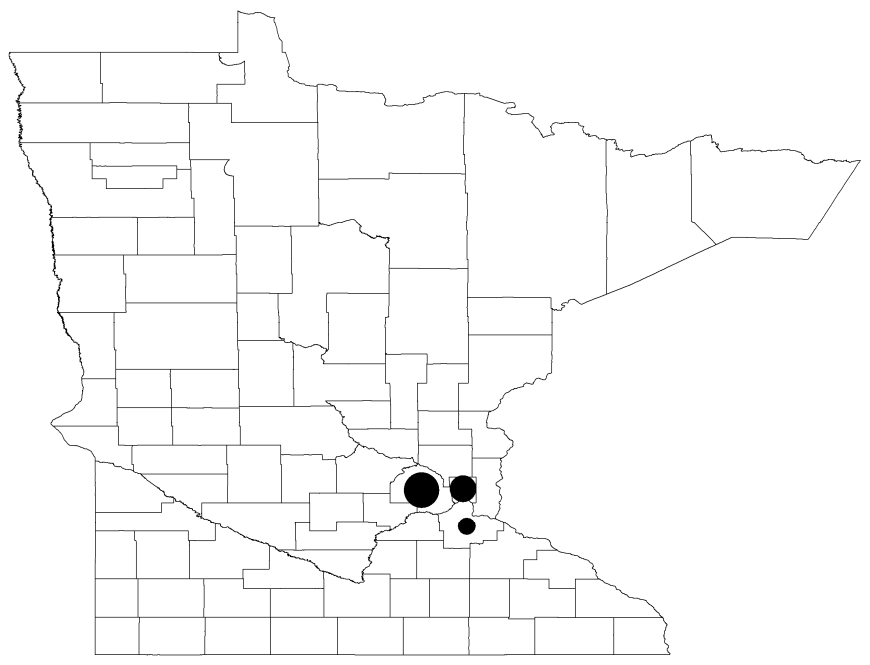

Legend

Statute 609.322 - Number of Convictions for Years 2007-09

- $1-4$

- 5 - 9

$10-13$

Fig. 2. The number of counties with a measurable number of sex trafficking court trials is very small during the first period 


\section{Solicitation, Inducement, and Promotion of Prostitution:}

Sex Trafficking

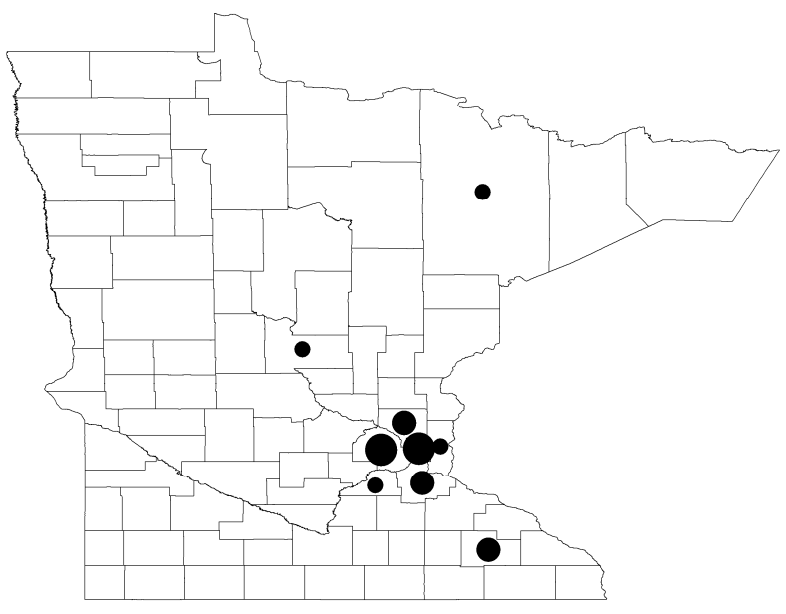

Legend

Statute 609.322 - Number of Convictions for Years 2010-12

- 1-2

$3-6$

7-12

Fig. 3. Few counties outside the Twin Cities area are reporting cases seen in court dealing with prostitution-related incidents

\section{Solicitation, Inducement,} and Promotion of Prostitution:

Sex Trafficking

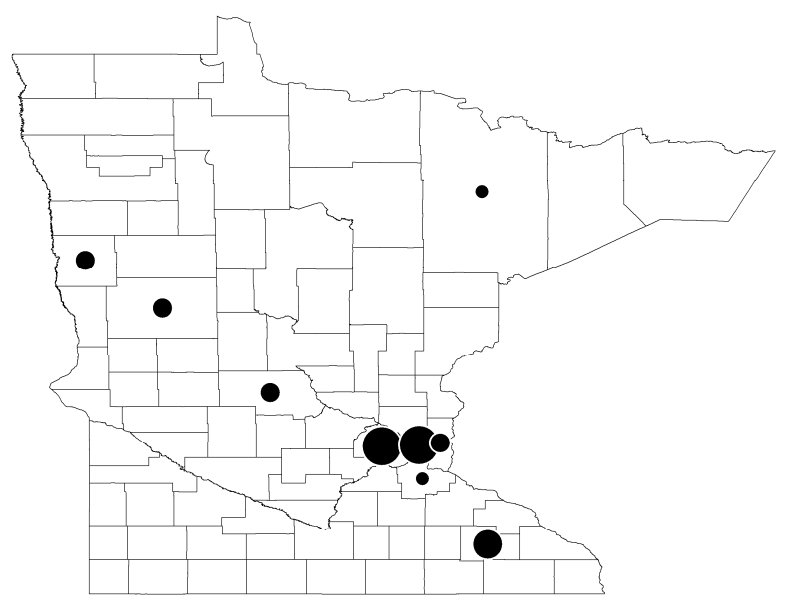

Legend

Statute 609.322 - Number of Convictions for Years 2013-15

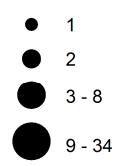

Fig. 4. Three counties in west central Minnesota report six court cases involving prostitution related offenses 
Apostolopoulos et al. (2012, p. 141) identifies "truck stops, highway rest and picnic areas, weigh and fuel stations, loading docks at trucking terminals and various legitimate (e.g., lodging) as well as dubious (e.g., adult entertainment) off-road establishments that cater to truckers" as the environments for a "social geography" of truck stop sex work. In the case of Minnesota, Martin et al. (2010, p. 1261) examined experiences, characteristics and risks of 117 adult female sex workers in Minneapolis and found that $23 \%$ of these women who traded sex in this city used truck stops as a venue. Reports produced by the U.S. Department of Justice revealed the break-up of a large prostitution ring involving minors transported to provide sexual services at truck stops, hotels and brothels during the mid-2000s in the Northeast and Upper Midwest parts of the country (Zhang, 2009, p. 179). The few exceptional sex trafficking cases I found occurring outside the Twin Cities metropolitan area between 2013 and 2015 affected the Interstate Highway 94 communities of St. Cloud, Fergus Falls and Moorhead, the Interstate Highway 35 community of Duluth and the Interstate Highway 90 community of Rochester. These communities have areas related to the transportation industry with characteristics similar to the "social geography" of truck stop sex work described by Apostolopoulos et al. (2012).
While the first three maps aggregate cases at the county level, Fig. 5-7 provide me with a better notion of which specific communities have been affected by the presence of incidents involving the solicitation, inducement and promotion of prostitution. In essence, the point maps permit me to use a quantitative tool for examining the spatial distribution of communities where the human trafficking related offense perpetrators were charged.

The point maps revealed differences between the first period (2007-2009) and the two most recent periods in the distribution of communities where individuals have been charged and prosecuted for the solicitation, inducement and promotion of prostitution. Most of the clustering of affected communities occurred during the first period in the Minneapolis-St. Paul metropolitan area. The overall trend in the distribution of cases dealing with statute 609.322 trafficking related crimes has been a decrease in the level of clustering of affected communities and an increase in the total number of cases seen in court for these offenses during the most recent periods. In order to confirm my visual inspection of the maps, a nearest neighbor index $(\mathrm{R})$ is calculated for each period using the locations of communities where the incidents took place (Table 1).

Table 1. A nearest neighbor index is calculated for each period using the locations of communities where the incidents took place.

\begin{tabular}{lllll}
\hline & Period & Nearest Neighbor Ratio (R) & z-score & p-value \\
\hline $\begin{array}{l}\text { There is less than 5\% likelihood that this clustered } \\
\text { pattern could be the result of random chance. }\end{array}$ & $2007-09$ & 0.673 & -2.344 & 0.019 \\
$\begin{array}{l}\text { There is less than 1\% likelihood that this clustered } \\
\text { pattern could be the result of random chance. }\end{array}$ & $2010-12$ & 0.544 & -4.774 & 0.000 \\
$\begin{array}{l}\text { There is less than 1\% likelihood that this clustered } \\
\text { pattern could be the result of random chance. }\end{array}$ & $2013-15$ & 0.563 & -4.342 & 0.000 \\
\hline
\end{tabular}

pattern could be the result of random chance.

\section{Solicitation, Inducement, and Promotion of Prostitution: Sex Trafficking}

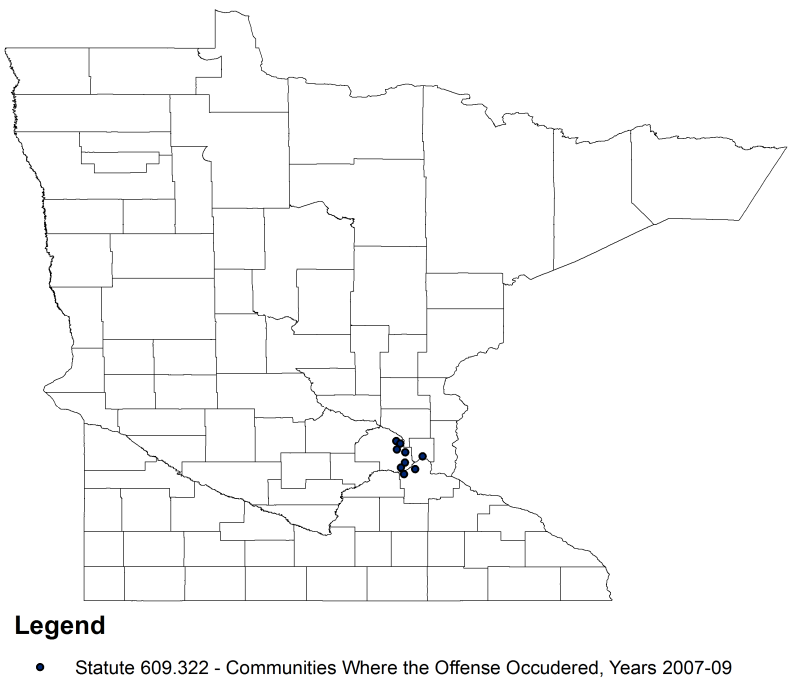

Fig. 5. Places affected by the presence of incidents involving the solicitation and promotion of prostitution during the first period 


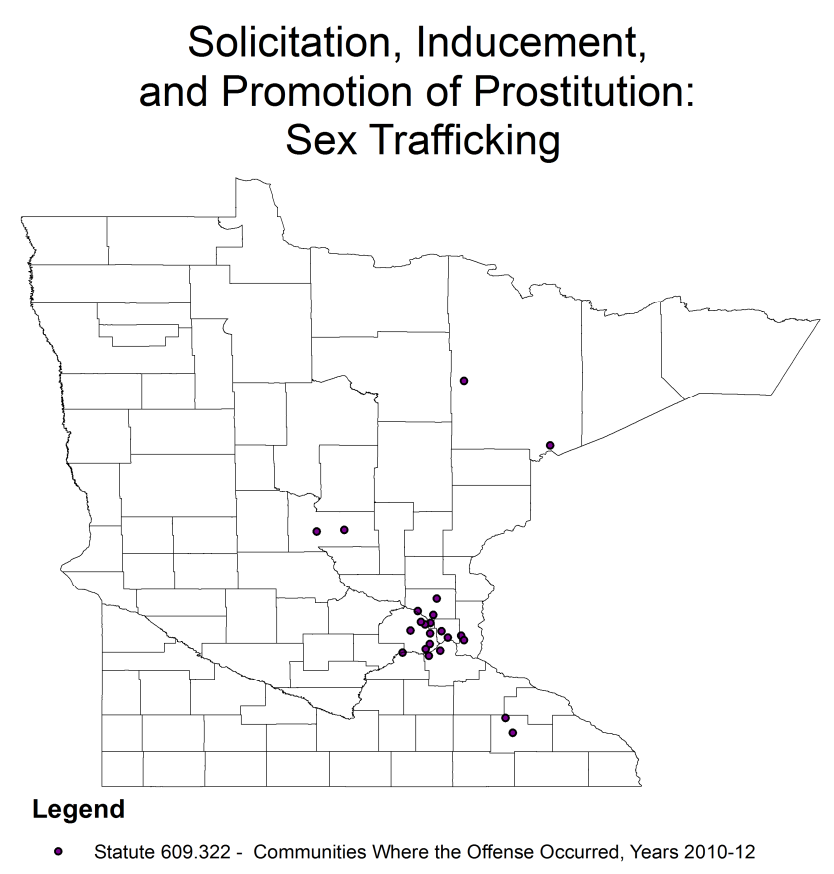

Fig. 6. Places affected by the presence of incidents involving the solicitation and promotion of prostitution during the second period

\section{Solicitation, Inducement, and Promotion of Prostitution: Sex Trafficking}

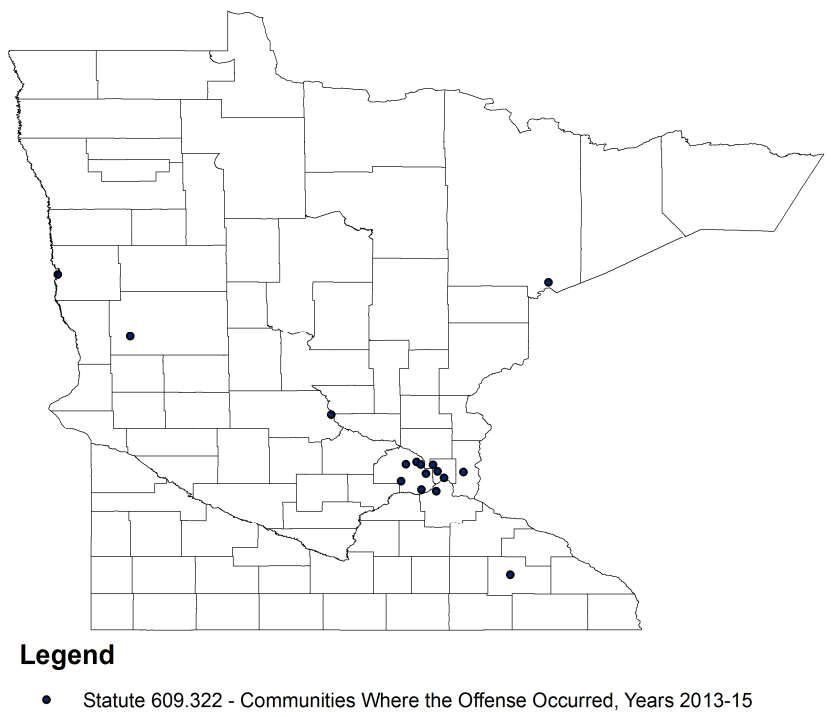

Fig. 7. Places affected by the presence of incidents involving the solicitation and promotion of prostitution during the third period

For the three periods dealing with data pertinent to statute 609.322 I have nearest neighbor index values less than one, indicating that the patterns of communities affected by solicitation, inducement and promotion of prostitution are more clustered than random, invalidating my visual inspection for the last two periods when I perceived at trend against clustering. Therefore, statistically speaking, I cannot claim that these human trafficking related cases are dispersing as I thought. In essence, Minnesotans have this problem clustering in the Twin Cities metropolitan area with few exceptional cases occurring outside, in greater Minnesota, during the last two periods. Dot maps confirm this trend that leans toward clustering (Fig. 5-7). 


\section{Solicitation of a Child}

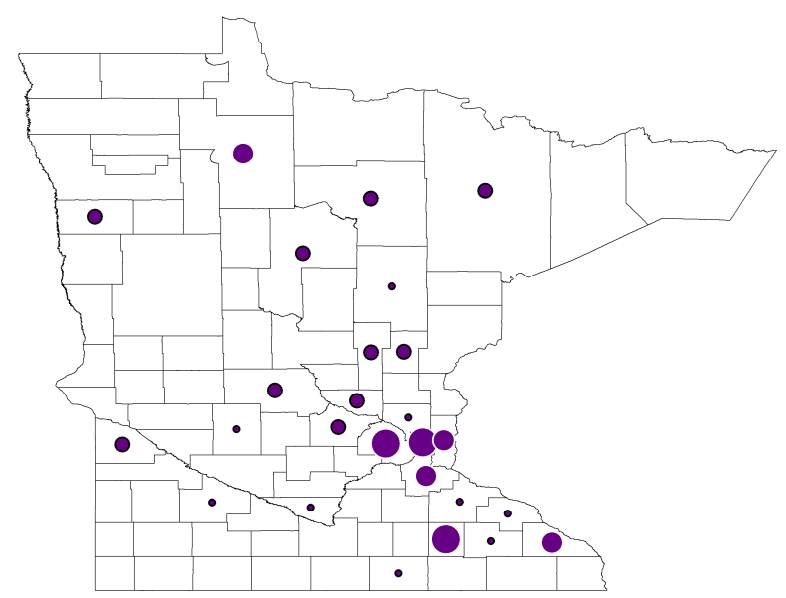

Legend

Statute 609.352 - Number of Convictions for Years 2007-09

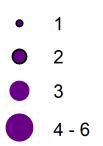

Fig. 8. Several counties in north central Minnesota reported cases dealing with this offense

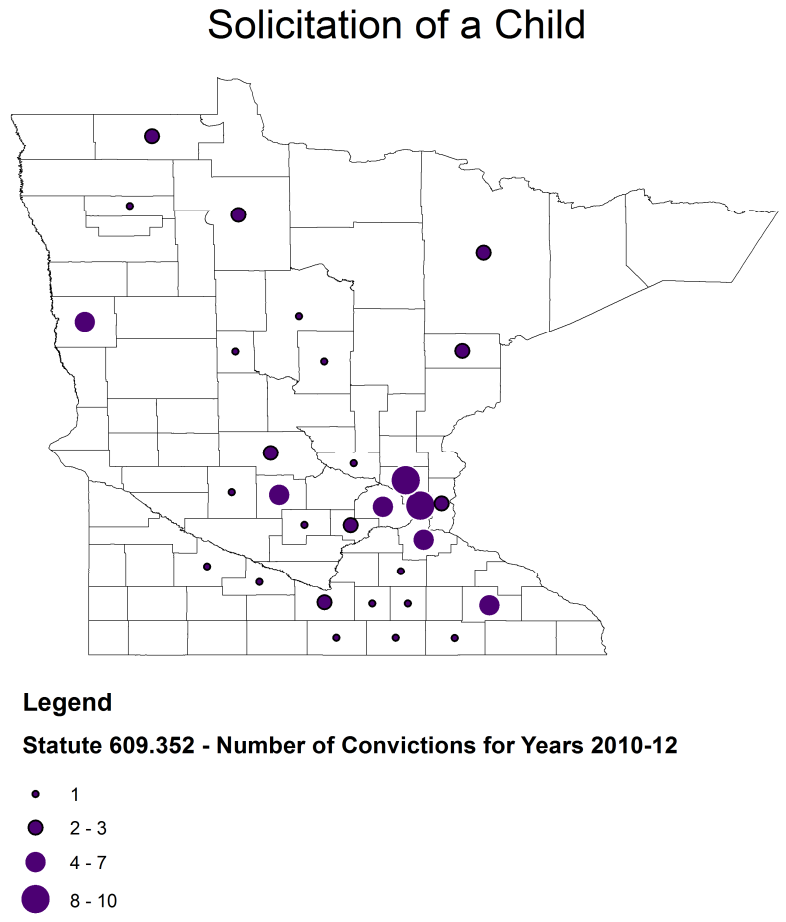

Fig. 9. The solicitation of children to engage in sexual conduct does not shows a trend toward clustering
Solicitation of a Child

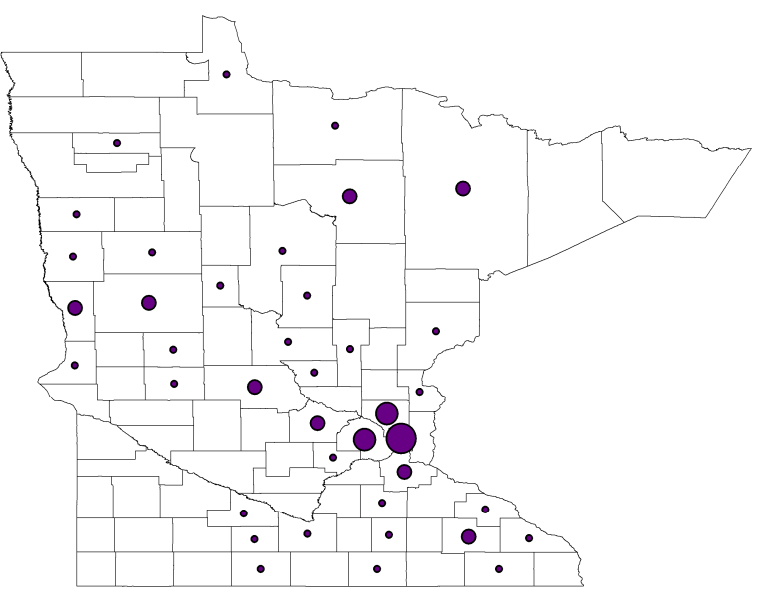

Legend

Statute 609.352 - Number of Convictions for Years 2013-15

- $1-2$

- $3-6$

$7-12$

$13-19$

Fig. 10. This offense does not discriminate type of region

Unlike the visual inspection of the first map for statute 609.322 , which has revealed a cluster of counties reporting most prostitution related cases in the Twin Cities metropolitan area, none of the proportional circle maps for cases involving charges of solicitation of children to engage in sexual conduct shows a trend toward clustering (Fig. 810). Several counties in north central Minnesota reported cases dealing with this offense. Unlike the proximity of important transportation corridors to areas affected by solicitation, inducement and promotion of prostitution, the solicitation of children to engage in sexual acts is happening in relatively remote counties of greater Minnesota. In other words, this human trafficking related offense does not discriminate in either type of community or region.

In order to confirm the visual inspection of the proportional circle maps dealing with solicitation of children to engage in sexual conduct, a nearest neighbor index $(R)$ is calculated for each period using the locations of communities where the incidents took place (Table 2).

A visual inspection of the dot maps (Fig. 11-13) pertinent to the statute dealing with solicitation of children to engage in sexual conduct reveals that these types of offenses do not necessarily cluster like the practice of prostitution. In fact, I can identify numerous cases of adult communication of sexually explicit materials to children randomly distributed in almost all regions of the state of Minnesota. The offenses related to this statute can include instances of electronic solicitation of children where a person 18 years of age or older uses the Internet and potential victims and offenders can live scattered all over a 
wide geographic area. There is the case a few years ago of a former Minneapolis police officer who lured adolescent girls into sexual encounters using social media such as Facebook and Skype and he eventually pleaded guilty to two counts of electronic solicitation of a minor (Zamora, 2015). Since a potential offender can communicate with a minor who lives hundreds of miles away, some of the victims can live outside the perpetrator's immediate community. For example, in 2012 a Ramsey County judge convicted a St. Paul man of solicitation of a child for sexual conduct via the Internet and the victim in this case was a boy living in Missouri who used Myspace to exchange writing and photos (Powell, 2012). Cole and Sprang (2015, p. 119) found that overall, $44.7 \%$ of respondents to a survey stated that at least one of the traffickers of the victims with whom they had worked had used the Internet to recruit victims, advertise commercial sex, make arrangements with customers for commercial sex and distribute pornography, regardless whether the individual is based in a rural or metropolitan environment.

Visual comparisons of the proportional circles and dot maps (Fig. 14-19) to track changes in the geographic distribution of cases dealing with the use of minors in sexual performances between 2007 and 2015 indicate that the presence of numerous convictions for this offense is not limited to the Twin Cities metropolitan area. Areas of Minnesota undergoing an increase in the number of cases of individuals using minors in sexual performances are outside the metropolitan counties of Hennepin and Ramsey, particularly in the northern part of the state and for the last period (2013-15) the northeastern county of St. Louis has the largest circle (Fig. 16). Also, I noticed that a decline in the number of cases occurred in the Twin Cities metropolitan area during that last period.

\section{Solicitation of a Child}

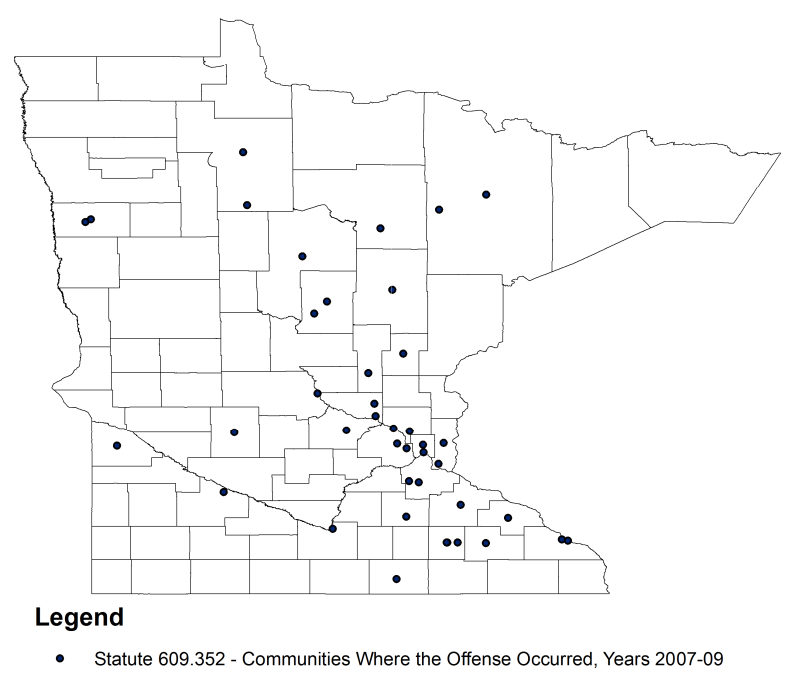

Fig. 11. This offense does not necessarily cluster like the practice of prostitution
In order to confirm the visual inspection of the proportional circles maps dealing with the use of minors in sexual performance, a nearest neighbor index $(R)$ is calculated for each period using the locations of communities where the incidents took place (Table 3). The nearest neighbor index supports the visual comparison and reveals that during the first two periods, cases involving the use of a minor for a sexual performance are randomly distributed. In contrast, a clustered pattern significantly different from random occurs during the 2013-15 period, with various cases detected in Minnesota's northeast region. The city of Hibbing is located in this area and a former elementary school teacher living in this community has been implicated in the possession of child pornography and the use of a minor in a sexual performance (Grinsteinner, 2013).

\section{Solicitation of a Child}

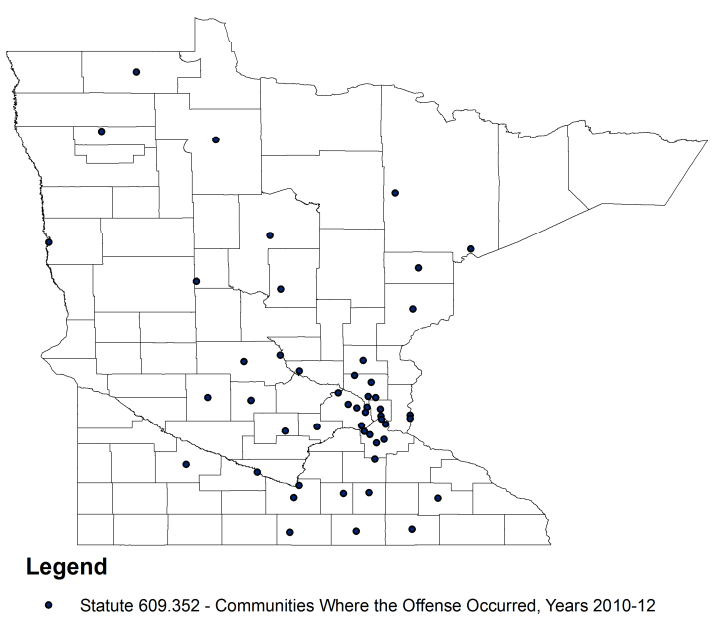

Fig. 12. Victims and offenders live scattered all over the state

\section{Solicitation of a Child}

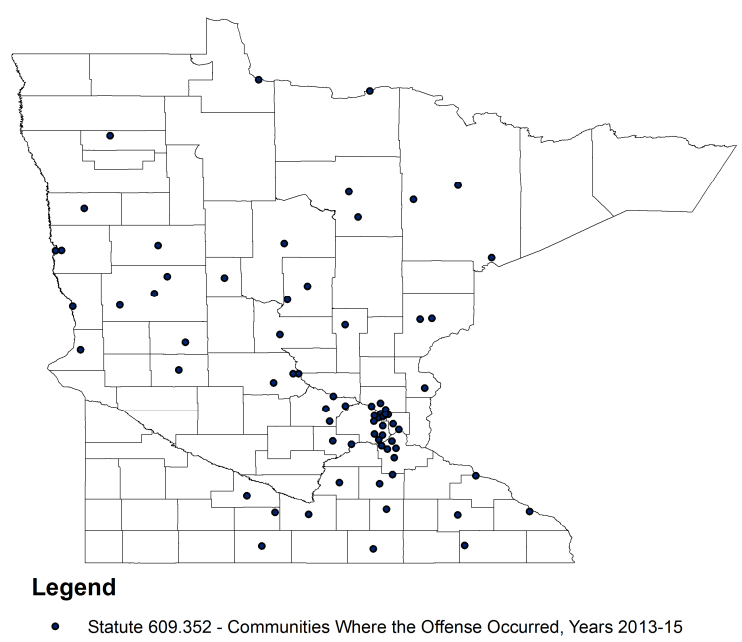

Fig. 13. Many cases of adult communication of sexually explicit materials to children are randomly distributed in almost all regions of Minnesota 
Table 2. A nearest neighbor index is calculated for each period using the locations of communities affected by solicitation of children to engage in sexual acts

\begin{tabular}{llrr}
\hline & \multicolumn{2}{c}{ Nearest Neighbor } \\
& Period & Ratio (R) & z-score \\
\hline The pattern does not appear to be significantly different than random. & $2007-09$ & 0.911 & -1.095 \\
The pattern does not appear to be significantly different than random. & $2010-12$ & 1.046 & 0.274 \\
The pattern does not appear to be significantly different than random. & $2013-15$ & 0.950 & 0.624 \\
\hline
\end{tabular}

\section{Use of a Minor in a Sexual Performance}

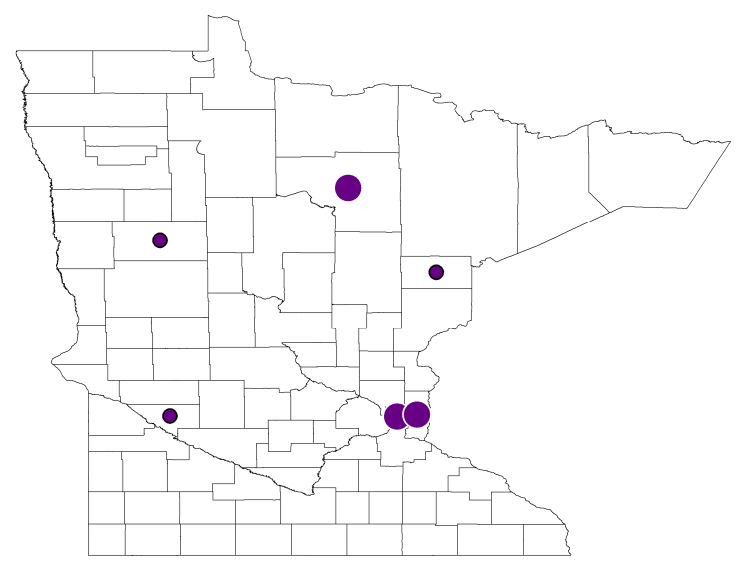

Legend

Statute 617.246 - Number of Cases for Years 2007-09

1

Fig. 14. The presence of numerous convictions for this offense is not limited to the Twin Cities metropolitan area

\section{Use of a Minor in a Sexual Performance}

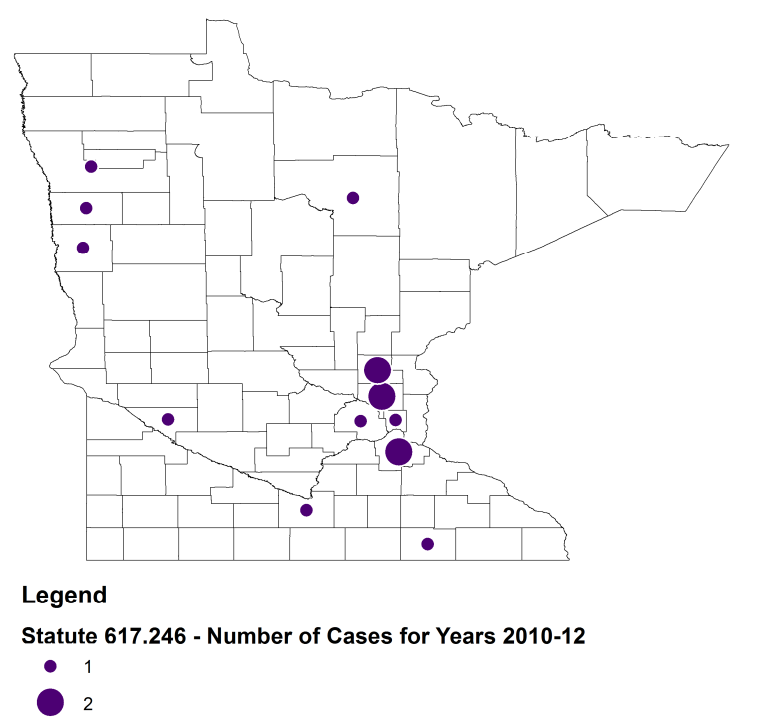

Fig. 15. New cases of individuals using minors in sexual performances are happening outside the Twin Cities.

\section{Use of a Minor in a Sexual Performance}

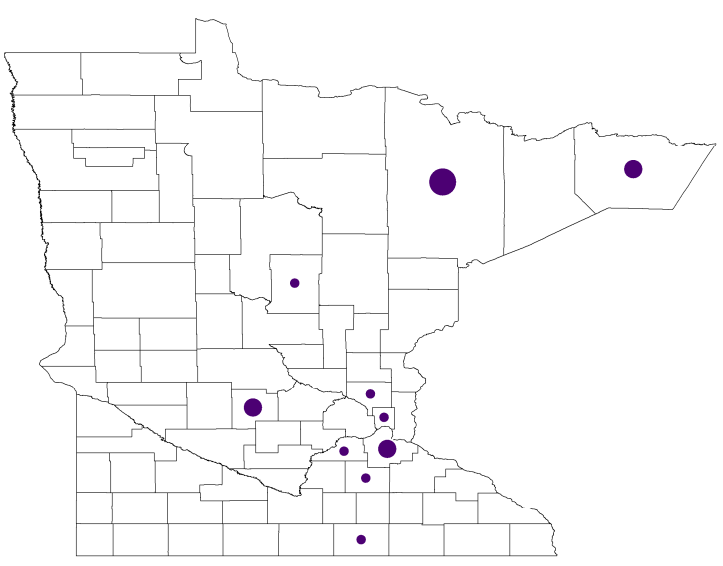

Legend

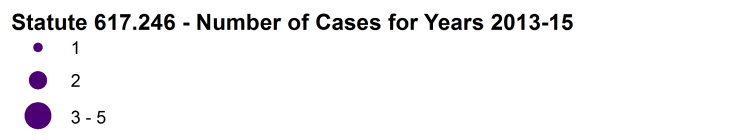

Fig. 16. An increase in the number of cases of individuals using minors in sexual performances is happening in the northern part of the state and for the last period, the northeastern county of St. Louis has the largest circle

\section{Use of a Minor in a Sexual Performance}

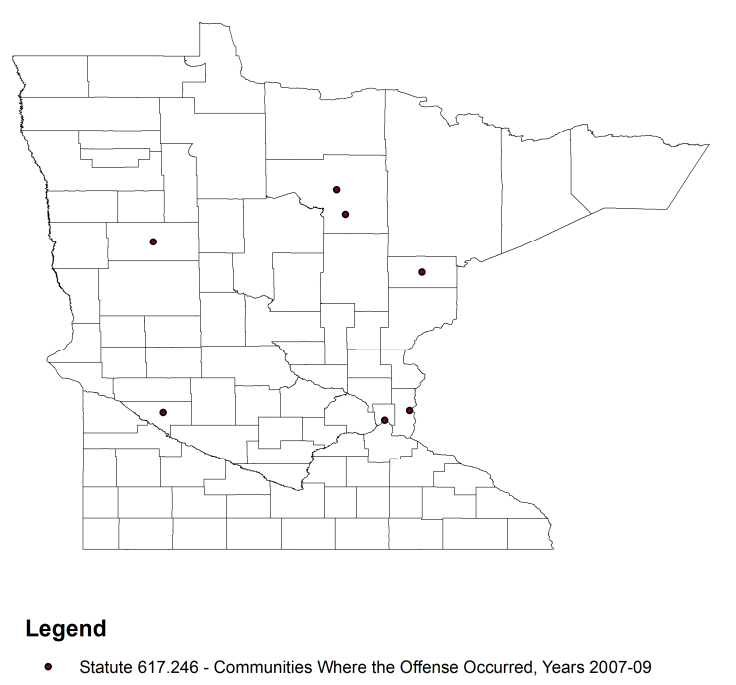

Fig. 17. Two communities in the northern county of Itasca have been affected by the use of minors in sexual performances 
Table 3. A nearest neighbor index is calculated for each period using the locations of communities affected by the use of minors in sexual performances

\begin{tabular}{|c|c|c|c|c|}
\hline & Period & $\begin{array}{l}\text { Nearest Neighbor } \\
\text { Ratio (R) }\end{array}$ & Z-score & p-value \\
\hline The pattern does not appear to be significantly different than random. & $2007-09$ & 1.316 & 1.815 & 0.070 \\
\hline The pattern does not appear to be significantly different than random. & $2010-12$ & 1.125 & 0.893 & 0.372 \\
\hline $\begin{array}{l}\text { There is less than } 1 \% \text { likelihood that this clustered pattern could be } \\
\text { the result of random chance. }\end{array}$ & $2013-15$ & 0.649 & -2.766 & 0.005 \\
\hline
\end{tabular}

\section{the result of random chance.}

\section{Use of a Minor in a Sexual Performance}

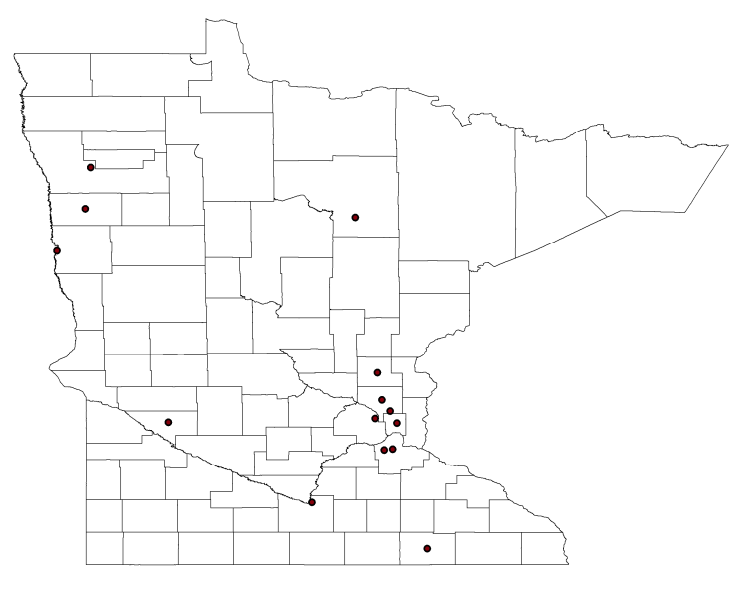

Legend

- Statute 617.246 - Communities Where the Offense Occurred, Years 2010-12

Fig. 18. The pattern of affected communities does not appear to be significantly different than random

\section{Use of a Minor in a Sexual Performance}

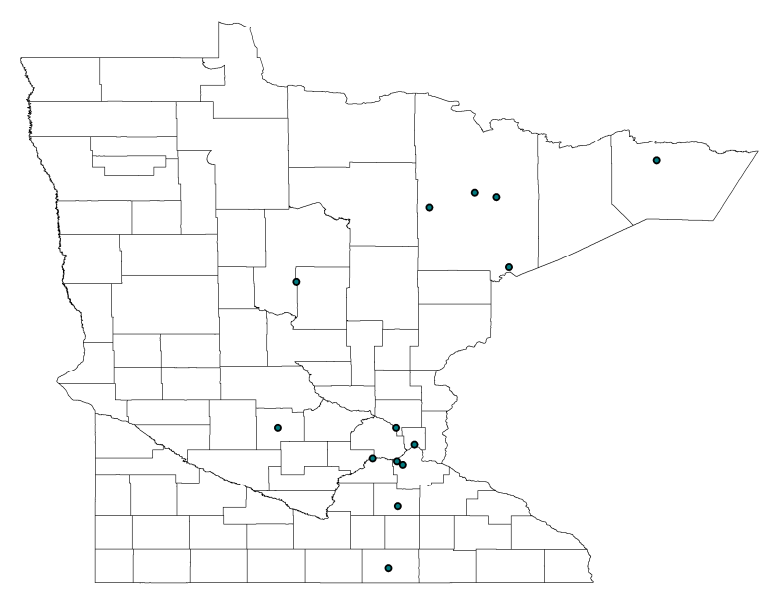

Legend

- Statute 617.246 - Communities Where the Offense Occurred, Years 2013-15

Fig. 19. A clustered pattern significantly different from random occurs during the 2013-15 period, with various cases detected in Minnesota's northeastern region

\section{Discussion}

According to the visual examination of the thematic maps and the nearest neighbor analyses, the greatest clustering for any of the offenses potentially related to human trafficking is for cases that involve statute 609.322 (Fig. 1-6). This statute deals with solicitation, inducement and promotion of prostitution; sex trafficking. The typical individual who participates in this trade is usually a contactdriven offender and for that reason, is reasonable to find in the maps clusters of places that have transient populations, transportation hubs and corridors and a considerable number of tourists visiting the region annually (Hubbard and Sanders, 2003; Bailey et al., 2011; McKewon, 2003). Tourists are among the type of clients Symanski (1974) listed as major sources of business for sex workers in Nevada during the early 1970s. In addition, Symanski (1974, p. 373) includes in this list of sex workers' clients "long distance and cross-country truck drivers, traveling salesmen and sportsmen, with truck drivers considered to be a large group of clients." All of these characteristics describe the regions where I find clusters of cases pertinent to the solicitation, inducement and promotion of prostitution in Minnesota from 2007 to 2015.

During the summer of 2015, a deceptive operation designed by various law enforcement agencies in Minnesota to arrest men soliciting sex work by using Craigslist and Backpage.com demonstrates how far individuals are willing to travel to converge at hotels in the Twin Cities area to support prostitution activity (Montemayor, 2015). In essence, the spatial movements of those driving regionally to buy sex from autonomous sex workers and trafficked individuals are happening in a centripetal fashion and the thematic maps for prostitution confirm this trend.

The maps and the spatial statistics (nearest neighbor analysis) dealing with solicitation of a child to engage in sexual conduct and the use of a minor in a sexual performance are less likely to display clusters of cases in metropolitan areas and transportation hubs. In the majority of cases, the patterns are random. I found only one clustered pattern for cases dealing with use of minors in a sexual performance for the period 2013-15. This cluster is located outside the Twin Cities, in the mining district of the Iron Ranges of the Lake Superior region, specifically 
Cook and St. Louis counties. For the other years I note, most of the time, these offenses occur in numerous communities outside the largest cities of Minnesota.

Based on news reports and the thematic maps' patterns, the Internet has become like a centrifugal force that has maintained a considerable number of child solicitation cases happening outside metropolitan areas traditionally linked to other sex crimes, such as prostitution. Cole and Sprang (2015), suggest that the use of the Internet by those responsible for sex trafficking of minors is making this type of illegal activity easily transferable and less dependent on the type of community.

\section{Conclusion}

Some of the offenders linked to statutes 609.352 and 617.246 are fantasy-driven offenders. This type of offender is primarily focused on online sexual communications and not necessarily demanding physical contact with their victims (Seto et al., 2012). For this reason, proximity to a large metropolitan area or transportation hub is not required for some of the forms of sexual interaction linked to these offenses that hurt minors. In other parts of the U.S. children who have been victims of sexual trafficking have been found in important agricultural regions. Some Minnesotan communities affected by cases of solicitation of children to engage in sexual conduct and the use of minors in sexual performances are located in agricultural areas such as the Red River and the Minnesota River valleys. Researchers have found that in some agricultural communities of California:

\section{Criminal networks in San Diego County control more than 50 brothels and outdoor farm labor sexual exploitation camps. Trafficked girls are sold to migrant farm workers, U.S. tourists and U.S. military personnel. In one typical case, caves made of reeds served as brothels at the edge of the fields. (Ugarte et al., 2004, p. 150)}

Something that is truly concerning about the geographic distribution of places in Minnesota where sexual exploitation of children related offenses have occurred is the non-metropolitan nature of many of these locations (Fig. 8-13). Many of the communities that have seen cases involving charges pertinent to the solicitation of children to engage in sexual conduct; communication of sexually explicit materials to children and the use of minors in sexual performances are outside the state's largest cities. Finkelhor (1994, p. 409) suggests that in places where there is a "lack of professional attention" and a small number of official reports, an underestimation of the prevalence of sexual abuse and misconduct can occur. Services to victims of trafficking and sexual abuse are not always available at the local level, particularly in more rural settings since "comprehensive services" are only available in large urban areas (Hopper 2004, p. 134). In addition, social services providers and law enforcement personnel in rural communities are less likely to receive the most advanced training to fight sex trafficking of minors in regions where dispersed and isolated communities are the norm (Cole and Sprang, 2015, p. 114). For this reason, it is very likely that many communities in Minnesota are in a vulnerable situation. It is crucial that an effective multiregional infrastructure is developed to guarantee the physical and emotional safety of sexual exploitation victims that have been removed from dangerous environments. The most vulnerable must be protected from any form of violence to make the prosecution of traffickers more successful and to establish trust with the victims (Ugarte et al., 2004, p. 160). A more geographically widespread presence of anti-trafficking organizations in Minnesota is imperative to rescue vulnerable members of society who are probably seeking help at this point. Cole and Sprang (2015) list several recommendations for nonmetropolitan communities where sex trafficking of minors can become a serious problem:

- Increase awareness, training and work experiences on sex trafficking of minors cases

- Improve or increase investment in the development of resources for effective response systems to incidents of sex trafficking of minors

- Improve early identification of familial participation in sex trafficking of minors in order to activate the appropriate child welfare remedies

However, as Tyldum and Brunovskis (2005, p. 25) point out "seeking help is a realistic option only for those who have and are aware of an active organization in their community." Truly active organizations need to play a very significant role "educating women about the true nature of the sex industry and providing them with other employment options" in order to make very difficult for traffickers victimizing them (Hodge, 2008, p. 150). Infrastructure developed to guarantee the physical and emotional safety of sexual exploitation and human trafficking victims can be very complex and at least need to include:

- Temporary and safe shelter as well as longer-term housing

- Physical and mental health care

- Public benefits 
- Legal assistance

- Drug and alcohol counseling

- Job training or assistance in obtaining employment

- Basic English language training

- Assistance should the victim chose to relocate or return to home country. (Logan et al., 2009, p. 22)

More research on this issue is necessary to increase consciousness about the problem. In essence, awareness is the key to combat this tragic trade and with communities more responsive to this kind of problem, there is a greater the likelihood that we will witness an increase in reported cases (Hopper, 2004). In addition, we need to remind ourselves that sex trafficking and the use of minors in sexual performances are not the only forms of human trafficking-related offenses. I have analyzed the occurrence of sex offenses related to three Minnesota law statutes because at this point this judicial branch data set is a relatively reliable piece of information and there is a significant lack of data for other forms of human trafficking-related activities. Unfortunately, there is a general tendency among government agencies to narrowly focus their attention to the presence of sex crimes and ignore the occurrence of other forms of exploitation. In numerous occasions, government agencies have unintentionally ignored the presence of individuals in need of social and legal services:

The identification of legitimate victims of human trafficking is therefore impacted by idealised representations of victimisation, as the strict criteria may simultaneously exclude legitimate victims and include autonomous workers. Simultaneously, this political preoccupation with the morality of commercial sex has diverted policy resources from the victims of non-sexual labour trafficking. (Wilson and O'Brien, 2016, p. 41)

Analyses of the narratives produced by victims and offenders who participated in the development of human trafficking studies reveal that among the proportion of trafficking types present in the victims' narratives, sex trafficking constitutes the largest single industry. For example, Wilson and O'Brien (2016, p. 37) have detected "an overt focus on trafficking for sexual exploitation" in which victims of sex trafficking are represented at a disproportionately high percentage of all trafficking types. Therefore, it is very important to bear in mind the diversity and complexities of human trafficking victims whenever anti-human trafficking infrastructures are developed. Further research that considers an in-depth compilation of victims' sociodemographic characteristics is needed to deepen our understanding of this tragic trade.

\section{Acknowledgement}

I would like to thank the staff of the Information Requests Program at the Minnesota Judicial Branch who provided valuable information for the completion of this article.

\section{Compliance with Ethical Standards}

The author declares that there is no conflict of interest. In addition, this article does not contain any studies with human participants performed by the author.

\section{References}

Apostolopoulos, Y., S. Sönmez, M. Shattell and J. Kronenfeld, 2012. Sex work in trucking milieux: "Lot lizards," truckers and risk. Nurs. Forum, 47: 140-152. DOI: 10.1111/j.1744-6198.2012.00272.x

Associated Press, 2010. Ex-Itasca county deputy sentenced for sex crimes. MPR News, St. Paul, Minnesota.

Bailey, A., I. Hutter and P. Huigen, 2011. The spatialcultural configuration of sex work in Goa India. Tijdschrift Voor Econom. Soc. Geografie, 102: 162-175. DOI: 10.1111/j.1467-9663.2010.00607.x

Batsyukova, S., 2007. Prostitution and human trafficking for sexual exploitation. Gender Issues, 24: 46-50. DOI: $10.1007 / \mathrm{s} 12147-007-9001-0$

Burt, J., G. Barber and D. Rigby, 2009. Elementary Statistics for Geographers. 1st Edn., Guilford Press, ISBN-10: 1572304847, pp: 653.

Cole, J. and G. Sprang, 2015. Sex trafficking of minors in metropolitan, micropolitan and rural communities. Child Abuse Neglect, 40: 113-123. DOI: 10.1016/j.chiabu.2014.07.015

Farrell, A., R. Pfeffer and K. Bright, 2015. Police perceptions of human trafficking. J. Crime Just., 38: 315-333. DOI: 10.1080/0735648X.2014.995412

Finkelhor, D., 1994. The international epidemiology of child sexual abuse. Child Abuse Neglect, 18: 409-417. DOI: 10.1016/0145-2134(94)90026-4

Grinsteinner, K., 2013. Former teacher to face prostitution, porn charges. Hibbing Daily Tribune, Hibbing, Minnesota.

Hepburn, S. and R. Simon, 2010. Hidden in plain sight: Human trafficking in the United States. Gender Issues, 27: 1-26. DOI: 10.1007/s12147-010-9087-7

Hodge, D.R., 2008. Sexual trafficking in the United States: A domestic problem with transnational dimensions. Soc. Work, 53: 143-152. DOI: 10.1093/sw/53.2.143

Hopper, E.K., 2004. Under identification of human trafficking victims in the United States. J. Soc. Work Res. Evaluat., 5: 125-136.

Hubbard, P. and T. Sanders, 2003. Making space for sex work: Female street prostitution and the production of urban space. Int. J. Urban Regional Res., 27: 75-89. DOI: $10.1111 / 1468-2427.00432$ 
Logan, T.K., R. Walker and G. Hunt, 2009. Understanding human trafficking in the United States. Trauma Violence Abuse, 10: 3-30. DOI: $10.1177 / 1524838008327262$

Martin, L., M. Hearst and R. Widome, 2010. Meaningful differences: Comparison of adult women who first traded sex as a juvenile versus as an adult. Violence Against Women, 16: 1252-1269. DOI: $10.1177 / 1077801210386771$

McGrew, J.C., A. Lembo and, C. Monroe, 2014. An Introduction to Statistical Problem Solving in Geography. 3rd Ed., Waveland Press, Long Grove, Illinois, ISBN-10: 1478611197.

McKewon, E., 2003. The historical geography of prostitution in Perth, Western Australia. Austral. Geographer, 34: 297-310. DOI: $10.1080 / 0004918032000152393$

MOJP, 2014. Human Trafficking in Minnesota: A Report to the Minnesota Legislature. Bureau of Justice Statistics, St. Paul, Minnesota.

Montemayor, S., 2015. Stings to fight sex trafficking lead to charges across the Metro. Star Tribune, Minneapolis, Minnesota.

Powell, J., 2012. St. Paul man guilty of cybersex with child. Star Tribune, Minneapolis, Minnesota.

Rogerson, P., 2015. Statistical Methods for Geography, 4th Edn., Sage, London, United Kingdom, ISBN-10: 1446295737.

Seto, M., J.M. Wood, K. Babchishin and S. Flynn, 2012. Online solicitation offenders are different from child pornography offenders and lower risk contact sexual offenders. Law Human Behav., 36: 320-330.

DOI: $10.1037 / \mathrm{h} 0093925$
Symanski, R., 1974. Prostitution in Nevada. Annals Assoc. Am. Geographers, 64: 357-377. DOI: $10.1111 / \mathrm{j} .1467-8306.1974 . t b 00985 . x$

Tyldum, G., 2010. Limitations in research on human trafficking. Int. Migrat., 48: 1-13. DOI: $10.1111 /$ j.1468-2435.2009.00597.x

Tyldum G. and A. Brunovskis, 2005. Describing the unobserved: Methodological challenges in empirical studies on human trafficking. Int. Migrat., 43: 17-34. DOI: 10.1111/j.0020-7985.2005.00310.x

Ugarte, M., L. Zarate and M. Farley, 2004. Prostitution and trafficking of women and children from Mexico to the United States. J. Trauma Pract., 2: 147-165. DOI: $10.1300 / J 189 v 02 n 0308$

Wilson, M. and E. O'Brien, 2016. Constructing the ideal victim in the United States of America's annual trafficking in persons reports. Crime Law Soc. Change, 65: 29-45. DOI: 10.1007/s10611-015-9600-8

Zamora, K., 2015. Ex-Minneapolis cop who lured girls online resentenced in Anoka County District Court. Star Tribune, Minneapolis, Minnesota.

Zhang, S., 2009. Beyond the 'Natasha' story - a review and critique of current research on sex trafficking. Global Crime, 10: 178-195.

DOI: $10.1080 / 17440570903079899$ 